\title{
NorDiNa 5(2): An extensive issue
}

Welcome to the second issue of NorDiNa this year. Since the very first issue was released at the 8th Nordic Research Symposium on Science Education in Aalborg 2005 we have managed to publish two issues each year except in 2006 then three issues saw the light of day. In other words, today you have NorDiNa the eleventh in your hands. As all other NorDiNa issues this one is a very special one. You may ask why, and the answer is: This issue touches a record by publishing as many as eight ordinary research papers, which has not been done since the very first issue. This reflects the increasing number of articles submitted to our journal, with a variety of nationality as well as content presented by the authors. Two of the papers have authors from Finland, two from Norway, three from Sweden and one paper has authors from both Norway and Sweden. Once more we are astonished over the great content span our Nordic authors present in their respective articles all in the field of science education.

Two of the papers present a content concerning chemistry education. Lise-Lotte Österlund and Margareta Ekborg present their empirical study under the heading Students' understanding of redox reactions in three situations. The students in upper secondary school used the electron model in the interviews and the authors found some indications that the students were able to transfer their knowledge between the classroom and an outdoor situation. Veli-Matti Vesterinen, Maija Aksela and Markku R. Sundberg have studied how current chemistry syllabi in the frame curricula for upper secondary education in three Nordic countries take into account topics related to the nature of chemistry. Their paper is entitled Nature of chemistry in the national frame curricula for upper secondary education in Finland, Norway and Sweden.

Two papers present learning and teaching about biological content. Ragnhild Lyngved studied the students' learning outcome from a context-based digital teaching unit, designed to introduce cloning. Her article has the following title Learning about cloning: developing student knowledge and interest through an interactive, context-based approach. Clas Olander has conducted a study where teachers and researchers collaborate on designing and validating topic-oriented teachinglearning sequences. His paper is entitled Teaching biological evolution - internal and external evaluation of learning outcomes.

The remaining four articles have a more general science educational content. Anders Jidesjö, Magnus Oscarsson, Karl-Göran Karlsson and Helge Strömdahl present Swedish results from 'the Relevance of Science Education' (ROSE) study. Their findings indicate that secondary science instruction seems to address only a minority of the students. The title of the article is Science for all or science for some: What Swedish students want to learn about in secondary science and technology and their opinions on science lessons. Are Turmo and Eyvind Elstad present a paper with the title What factors make science test items especially difficult for students from minority groups? 
The authors point out substantial gaps in science performance between majority and minority students in tests used in primary school. Further, they identify minority friendly items by which the gap can be reduced significantly. Maija Ahtee, Liisa Suomela, Kalle Juuti, Jarkko Lampiselkä and Jari Lavonen write in their article that in spite of scientific observation playing a central part in the formation of scientific knowledge there are only a few studies that focus on the problems in making observations. The paper has the following title Primary school student teachers' views about making observations. Finally in the paper with authors from Sweden and Norway, Bo Dahlin, Edvin Østergaard and Aksel Hugo take a phenomenological approach in a discussion of the philosophical grounds of science education. They conclude that the field is in need of reversals of primacy in their article An argument for reversing the bases of science education - A phenomenological alternative to cognitionism.

We are happy to again present to you as a NorDiNa reader this great span of important issues of science education in a Nordic context.

Enjoy your read!

Anita Wall.

Anita Wallin

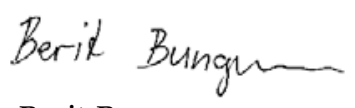

Berit Bungum
Byom Andersm

Björn Andersson 